\title{
Association of Lifestyle Factors and Sperm Motility in Adults from an Ethnic Minority Region of Southwest China
}

\author{
Linfeng Mo1, Junyi Tang1, Jia Liư1, Liangzhao Liư ${ }^{1}$, Jingyu Li², Yonghua He ${ }^{1 *}$ \\ ${ }^{1}$ Department of Epidemiology and Statistics, School of Public Health, Guilin Medical University, Guilin, China \\ ${ }^{2}$ Reproductive Health Center, Liuzhou Maternity and Child Healthcare Hospital, Liuzhou, China \\ Email: *hyhup@shmu.edu.cn
}

How to cite this paper: Mo, L.F., Tang, J.Y., Liu, J., Liu, L.Z., Li, J.Y. and He, Y.H. (2021) Association of Lifestyle Factors and Sperm Motility in Adults from an Ethnic Minority Region of Southwest China. Advances in Reproductive Sciences, 9, 149159

https://doi.org/10.4236/arsci.2021.92015

Received: April 13, 2021

Accepted: May 28, 2021

Published: May 31, 2021

Copyright $\odot 2021$ by author(s) and Scientific Research Publishing Inc. This work is licensed under the Creative Commons Attribution International License (CC BY 4.0).

http://creativecommons.org/licenses/by/4.0/

\begin{abstract}
Objectives: To understand sperm motility in adults and its association with lifestyle in an ethnic minority area in Southwest China. Methods: A hospital-based cross-sectional study to assess sperm motility in male adults was conducted at the Reproductive Health Center from January 2018 to May 2019. The data was collected with a questionnaire and semen quality was analyzed with Computer-Aided Sperm Analysis system (CASA). Analysis of covariance (ANCOVA) was used to measure the relationship between lifestyle factors and sperm motility. Results: A total of 349 people were recruited. Dietary celery intake was significantly related to the increase of sperm progressive motility and total motility ( $\beta=7.00,95 \%$ CI: $1.59,12.42$ and $\beta=7.26$, $95 \%$ CI: $1.45,13.07$, respectively). Cola consumption was associated with increased sperm progressive motility ( $\beta=9.71,95 \%$ CI: $1.46,17.96)$. Frequent use of plastic bags for meat food storage $(\beta=-5.56,95 \%$ CI: $-10.61,-0.51)$, industry work $(\beta=-5.64,95 \% \mathrm{CI}:-11.21,-0.07)$, organic disease $(\beta=-6.14$, 95\% CI: $-11.00,-1.28)$ and sedentary lifestyle $(\beta=-5.92,95 \%$ CI: -10.66 , -1.17 for $3-5 \mathrm{~h} / \mathrm{d}$ and $\beta=-6.04,95 \% \mathrm{CI}:-11.60,-0.47$ for $\geq 5 \mathrm{~h} / \mathrm{d}$, respectively) were related with the decreased sperm progressive motility. Meanwhile, using plastic bags for meat food storage $(\beta=-6.37,95 \% \mathrm{CI}:-11.79$, $-0.95)$, industry work $(\beta=-7.96,95 \% \mathrm{CI}:-13.94,-1.98)$ and sedentary lifestyle $(\beta=-5.51,95 \% \mathrm{CI}:-10.60,-0.42$ for $3-5 \mathrm{~h} / \mathrm{d}$ and $\beta=-6.03,95 \% \mathrm{CI}$ : $-12.01,-0.06$ for $\geq 5 \mathrm{~h} / \mathrm{d}$, respectively) were also risk factors for total motility. Conclusions: Some modifiable lifestyle factors such as job title, cola consumption, dietary celery intake, plastic bags for meat food storage, and sedentary hours were linked to male sperm motility, indicating that changing these lifestyles may improve it.
\end{abstract}




\section{Keywords}

Lifestyles, Sperm Motility, Semen Quality, Ethnic Minority, Epidemiology

\section{Introduction}

About $10 \%$ to $15 \%$ of couples of childbearing ages suffer from infertility in the world, of which about $50 \%$ is attributed to the man [1]. Semen quality is one of the most direct indicators to evaluate male reproductive health. The declining trend of semen quality with time has been a public concern since its first report in the 1990s [2].

Transitions of lifestyle [3] [4] are generally considered to related sperm quality decline. However, there are studies with inconsistent results as yet [5]. Even some important daily behaviors such as smoking, alcohol drinking, or coffee drinking, are not confirmed the association with sperm quality [5] [6]. Thus, further study to reveal the relationship between lifestyle and semen quality is urgent.

Liuzhou is one of the industrial regions in southwest China, while about $20 \%$ of the region's people engaged in industry and more (about 40\%) in agriculture. People of ethnic minorities account for about $50 \%$ of the local population, sharing some different lifestyles, e.g., little caffeinated beverages drinking but much fragrant spice intake [7] compared with those in most parts of China. However, there have been no reports on the relationship between lifestyle factors such as spice intake and semen quality in this region [8] [9]. Therefore, a unique insight into the correlation between semen quality of adults and lifestyle is possible by research on this population.

Because sperm motility is the main parameter of semen quality and is generally considered unaffected by abstinence duration [10] [11], we analyzed the progressive sperm motility (PR, \%) and total sperm motility (PR + NP, \%) among 349 adults from the Reproductive Health Center of Maternity and Child Healthcare Hospital of Liuzhou in the present study, to explore its association with lifestyle.

\section{Materials and Methods}

\subsection{Study Design and the Population}

A total of 369 male visitors at the Center from January 2018 to May 2019 for pre-marital checkup or pregnancy problems were chosen for the hospital-based cross-sectional study (according to formula:

$$
n=\frac{Z_{1-\alpha / 2}^{2} \times p q}{d^{2}}(\alpha=0.05, p=50 \%, q=1-p, d=0.1 p),
$$

400 samples were estimated in need, and 369 volunteers were actually collected). Among them, 20 men were excluded because of incomplete semen anal- 
ysis data, clinical diagnosis of chronic diseases, genetic diseases, neoplasms or exposure to chemotherapy or radiotherapy treatments. Eligible participants are

20 - 45 years old, residing in this district over 1 year. They were asked to sign informed consent and to fill the male reproductive health questionnaire under the direction of a qualified investigator at the hospital.

\subsection{Semen Collection and Analysis}

The participants were asked to masturbate for the collection of semen samples in sterile plastic container for 3 times, each time after about 5 days of abstinence (with average abstinence duration of $5.7 \pm 0.6$ days) because of the variability on semen parameters. The semen sample got liquefied in a $37^{\circ} \mathrm{C}$ thermostatic bath, and then assessed using Computer-Aided Sperm Analysis system (CASA, WLJY 9000, New Century Science and Tech Dev. Beijing, China) within $60 \mathrm{~min}$ of the collection.

For quality control, standard operation procedures were made and applied for semen collection, storage and testing, based on "WHO laboratory manual for the Examination and processing of human semen, fifth edition" (WHO, 2010). Testing semen samples was performed by a licensed laboratory technician with identical calibrated instruments.

\subsection{Questionnaire}

The questionnaire for this project has been used by this hospital for years, mainly including detailed information on demographics, education, living conditions and behaviors such as consumption of tobacco, alcohol and drug, job title, and health history.

Lifestyle parameters are defined and measured as the following. All participants' weight and height were measured, and body mass index (BMI) was calculated $\left(\mathrm{kg} / \mathrm{m}^{2}\right)$. BMI was categorized to 4 groups based on the World Health Organization (WHO) criteria, i.e., underweight $\left(<18.5 \mathrm{~kg} / \mathrm{m}^{2}\right)$, normal weight $(18.5$ $\left.24.9 \mathrm{~kg} / \mathrm{m}^{2}\right)$, overweight $\left(25.0-29.9 \mathrm{~kg} / \mathrm{m}^{2}\right)$ and obese $\left(\geq 30 \mathrm{~kg} / \mathrm{m}^{2}\right)$. Self-reported history of organic reproductive diseases covered cryptorchidism, urinary tract infections, prostatitis, varicocele or urogenital surgery.

Smoker is one who has continuously or accumulatively smoked for six months or more till the investigation day. Self-reported main alcohol consumption means someone drank $200 \mathrm{ml}$ beer, or $100 \mathrm{ml}$ fruit juice wine or $25 \mathrm{ml}$ white wine (mainly rice wine) or above, at least once a week for more than six months. Drinking tea (tea consumption of 5 to $8 \mathrm{~g} / \mathrm{day}$ ), cola (500 $\mathrm{ml} /$ time), coffee (a tin, about $236 \mathrm{ml} /$ time $)$ and dietary celery intake (120 g/time) or fruit intake (250 g/time) referred to at least once a week over the last 6 months.

Using microwave oven means everyday usage not less than $3 \mathrm{~min}$ during the last 6 months (at the electromagnetic radiation frequency of $915 \pm 25 \mathrm{MHz}$ or $2450 \pm 50 \mathrm{MHz}$ according to the national standard). Using plastic bags for meat food storage means everyday usage during the last 6 months. 


\subsection{Statistical Analysis}

Firstly, univariate analysis was performed to check factors related to PR and PR $+\mathrm{NP}$ of sperm because of its normal distribution. Linear regression analysis was carried out for continuous independent variables, one-way analysis of variance (ANOVA) was used for multi-classification independent variables, and independent sample t-test was applied for two-classification independent variables. Secondly, analysis of covariance (ANCOVA) was conducted to check effects of all potential risks on $\mathrm{PR}$ and $\mathrm{PR}+\mathrm{NP}$.

Data were double entered and checked with EpiData 3.1 and all statistical analysis were performed on SPSS version 16.0 (SPSS Inc., Chicago, IL, USA). Descriptive results are expressed as mean (standard deviation, SD) or frequency (\%). All the tests were two-sided, with $\mathrm{p}<0.05$ as the significant level.

\section{Results}

\subsection{Characteristics and Sperm Motility among the Study Population}

A total of 349 objects were qualified for the project. The univariate analysis of general characteristics and sperm motility of the study population was summarized in Table 1. They were at the age of $35.4 \pm 5.1$ years old (95\% CI: 34.82, 35.90 ) with BMI of $23.5 \pm 3.4 \mathrm{~kg} / \mathrm{m}^{2}$ (95\% CI: 23.14, 23.86). Almost all research objects were married or cohabiting (only 2 were single). The PR sperm of the population was $41.6 \% \pm 20.1 \%$ and PR $+\mathrm{NP}$ was $63.4 \% \pm 21.4 \%$. Furthermore, $115(33.0 \%)$ and $53(15.2 \%)$ samples were under the lower reference limits of PR (32\%) and PR + NP (40\%), respectively. Occupation title and history of organic reproductive diseases were significantly associated with $\mathrm{PR}$ or $\mathrm{PR}+\mathrm{NP}$ (all $\mathrm{p}<$ 0.05), while age, BMI (categorized either in standards of WHO or China), ethnicity and education level were not (all $\mathrm{p}>0.05$ ).

\subsection{Lifestyles and Sperm Motility}

About $54.7 \%$ of objects were smokers, and most of them (73.9\%) drank wine, while little of them enjoyed cola (6.9\%) or coffee $(1.1 \%)$. Over $20 \%$ had celery intake every day (Table 2).

Cola drinking, using microwave oven, using plastic bags for meat products storage, dietary celery intake, and prolonged sitting showed significant association with sperm motility (Table 2). Cola drinking, using microwave oven and dietary celery intake was positively associated with PR, and PR + NP (all p < $0.05)$, while using plastic bags for meat products storage and sedentary time were negatively correlated with PR and PR + NP (all p $<0.05)$.

\subsection{Multivariate Analysis (ANCOVA) of Sperm Motility}

To adjust confounding, all variables were incorporated into multivariate ANCOVA models (Table 3). In the final model, negative associations of PR ( $\beta=$ -5.92 or $\beta=-6.04$, respectively, $\mathrm{p}<0.05)$ and $\mathrm{PR}+\mathrm{NP}(\beta=-5.51$ or $\beta=-6.03$, 
respectively, $\mathrm{p}<0.05$ ) with sedentary time more than $3 \mathrm{~h} /$ day or $5 \mathrm{~h}$ /day was found. Industry work $(\beta=-5.64$ or $\beta=-7.96$, respectively, $\mathrm{p}<0.05)$, using plastic bags for meat food storage $(\beta=-5.56$ or $\beta=-6.37$, respectively, $\mathrm{p}<0.05)$ were significantly associated with low $\mathrm{PR}$ and $\mathrm{PR}+\mathrm{NP}$ yet. Meanwhile, men with a history of organic disease were also found harmful to $\mathrm{PR}(\beta=-6.14, \mathrm{p}<$ 0.05)

Dietary celery intake was beneficial to PR or PR + NP, i.e., leading to increases of $7.0 \%$ (95\% CI: $1.59,12.42 ; \mathrm{p}=0.011)$ and $7.3 \%$ (95\% CI: $1.45,13.07 ; \mathrm{p}=$ 0.015), respectively. Cola drinking was also found to be association with increased PR at 9.7\% (95\% CI: 1.46, 17.96; $\mathrm{p}=0.021)$. There were no significant differences observed between microwave oven using with sperm motility.

Table 1. Univariate analysis on sperm motility by population characteristics.

\begin{tabular}{|c|c|c|c|c|c|c|c|c|}
\hline \multirow{2}{*}{\multicolumn{2}{|c|}{ Characteristics }} & \multirow{2}{*}{ n (\%) } & \multicolumn{3}{|c|}{ Progressive motility (PR, \%) } & \multicolumn{3}{|c|}{ Total motility (PR + NP, \%) } \\
\hline & & & Mean \pm SD & $t / F$ & $\mathbf{P}$ & Mean \pm SD & $t / F$ & $\mathbf{P}$ \\
\hline \multicolumn{2}{|c|}{ Sperm motility $(\mathrm{PR}, \mathrm{PR}+\mathrm{NP})$} & $349(100.0)$ & $41.6 \pm 20.1$ & & & $63.4 \pm 21.4$ & & \\
\hline \multirow{3}{*}{ Age $(\text { years })^{\mathrm{a}}$} & $\leq 34$ & $169(48.4)$ & $42.1 \pm 19.9$ & & & $63.6 \pm 20.1$ & & \\
\hline & $35-39$ & $105(30.1)$ & $44.2 \pm 19.9$ & 2.809 & 0.062 & $65.3 \pm 20.7$ & 1.048 & 0.353 \\
\hline & $\geq 40$ & $75(21.5)$ & $37.1 \pm 20.4$ & & & $60.2 \pm 24.9$ & & \\
\hline \multirow{3}{*}{ Ethnicity $^{\mathrm{a}}$} & Han & $155(44.4)$ & $41.1 \pm 19.4$ & & & $63.2 \pm 20.8$ & & \\
\hline & Zhuang & $148(42.4)$ & $41.3 \pm 21.2$ & 0.634 & 0.531 & $62.4 \pm 22.3$ & 0.935 & 0.393 \\
\hline & Others & $46(13.2)$ & $44.8 \pm 19.0$ & & & $67.3 \pm 20.8$ & & \\
\hline \multirow{3}{*}{ Education $^{a}$} & Junior school and below & $176(50.4)$ & $42.4 \pm 20.3$ & & & $64.7 \pm 21.4$ & & \\
\hline & High or technical school & $80(22.9)$ & $39.3 \pm 20.4$ & 0.717 & 0.489 & $61.0 \pm 21.7$ & 0.848 & 0.429 \\
\hline & College and above & $93(26.6)$ & $42.3 \pm 19.6$ & & & $62.9 \pm 21.2$ & & \\
\hline \multirow{3}{*}{ Job title ${ }^{a}$} & Industry worker & $73(20.9)$ & $37.1 \pm 18.7$ & & & $57.2 \pm 21.9$ & & \\
\hline & Farmer & $121(34.7)$ & $40.6 \pm 21.3$ & 3.650 & $0.027^{*}$ & $62.8 \pm 22.7$ & 5.127 & $0.006^{*}$ \\
\hline & Others & $155(44.4)$ & $44.6 \pm 19.4$ & & & $66.8 \pm 19.5$ & & \\
\hline \multirow{4}{*}{$\begin{array}{l}\text { BMI (on WHO } \\
\left.\text { criteria, } \mathrm{kg} / \mathrm{m}^{2}\right)^{\mathrm{a}}\end{array}$} & Underweight $(<18.5)$ & $19(5.4)$ & $46.0 \pm 17.1$ & \multirow{4}{*}{0.458} & \multirow{4}{*}{0.712} & $67.0 \pm 16.2$ & \multirow{4}{*}{0.190} & \multirow{4}{*}{0.903} \\
\hline & Normal weight (18.5 - 24.9) & $217(62.2)$ & $41.2 \pm 20.3$ & & & $63.2 \pm 21.8$ & & \\
\hline & Overweight (25.0 - 29.9) & $98(28.1)$ & $42.3 \pm 20.8$ & & & $63.2 \pm 21.8$ & & \\
\hline & Obese $(\geq 30.0)$ & $15(4.3)$ & $38.9 \pm 16.9$ & & & $62.6 \pm 20.7$ & & \\
\hline \multirow{4}{*}{$\begin{array}{l}\text { BMI (on China } \\
\left.\text { criteria, } \mathrm{kg} / \mathrm{m}^{2}\right)^{\mathrm{a}}\end{array}$} & Underweight $(<18.5)$ & $19(5.4)$ & $46.0 \pm 17.1$ & \multirow{4}{*}{1.447} & \multirow{4}{*}{0.229} & $67.0 \pm 16.2$ & \multirow{4}{*}{1.740} & \multirow{4}{*}{0.168} \\
\hline & Normal weight (18.5 - 23.9) & $178(51.0)$ & $40.1 \pm 20.2$ & & & $61.7 \pm 21.7$ & & \\
\hline & Overweight (24.0 - 27.9) & $118(33.8)$ & $44.1 \pm 19.8$ & & & $66.4 \pm 20.1$ & & \\
\hline & Obese $(\geq 28.0)$ & $34(9.7)$ & $38.9 \pm 21.7$ & & & $59.6 \pm 26.0$ & & \\
\hline \multirow{2}{*}{$\begin{array}{l}\text { With organic } \\
\text { reproductive diseases }\end{array}$} & No & $267(76.5)$ & $43.0 \pm 20.9$ & \multirow{2}{*}{2.467} & \multirow{2}{*}{$0.015^{*}$} & $64.6 \pm 22.1$ & \multirow{2}{*}{1.933} & \multirow{2}{*}{0.054} \\
\hline & Yes & $82(23.5)$ & $37.4 \pm 16.8$ & & & $59.4 \pm 18.9$ & & \\
\hline
\end{tabular}

BMI: Body mass index; SD: Standard deviation; ${ }^{\mathrm{a} O n e-w a y ~ a n a l y s i s ~ o f ~ v a r i a n c e ~ w a s ~ u s e d ; ~}{ }^{\mathrm{b}}$ Independent-samples t-test was used; ${ }^{*} \mathrm{P}<0.05$. 
Table 2. Univariate analysis on sperm motility by lifestyle.

\begin{tabular}{|c|c|c|c|c|c|c|c|c|}
\hline \multirow{2}{*}{\multicolumn{2}{|c|}{ Lifestyle }} & \multirow{2}{*}{$\mathrm{n}(\%)$} & \multicolumn{3}{|c|}{ Progressive motility (PR, \%) } & \multicolumn{3}{|c|}{ Total motility (PR + NP, \%) } \\
\hline & & & Mean \pm SD & $t / F$ & $\mathbf{P}$ & Mean \pm SD & $t / F$ & $\mathbf{P}$ \\
\hline \multicolumn{2}{|c|}{ Sperm motility $(\mathrm{PR}, \mathrm{PR}+\mathrm{NP})$} & $349(100.0)$ & $41.6 \pm 20.1$ & & & $63.4 \pm 21.4$ & & \\
\hline \multirow{3}{*}{ Smoking (piece/day) ${ }^{\mathrm{a}}$} & Never & $158(45.3)$ & $40.5 \pm 20.9$ & & & $62.0 \pm 22.0$ & & \\
\hline & $<20$ & $79(22.6)$ & $43.4 \pm 19.1$ & 0.576 & 0.563 & $65.6 \pm 20.9$ & 0.745 & 0.475 \\
\hline & $\geq 20$ & $112(32.1)$ & $42.0 \pm 19.8$ & & & $63.8 \pm 21.1$ & & \\
\hline \multirow{4}{*}{ Alcohol consumption ${ }^{\mathrm{a}}$} & Never & $91(26.1)$ & $38.7 \pm 20.7$ & \multirow{4}{*}{1.131} & \multirow{4}{*}{0.336} & $60.0 \pm 21.8$ & \multirow{4}{*}{1.159} & \multirow{4}{*}{0.325} \\
\hline & Rice wine & $159(45.6)$ & $43.3 \pm 20.5$ & & & $65.2 \pm 22.1$ & & \\
\hline & Red wine & $26(7.4)$ & $43.7 \pm 17.7$ & & & $64.3 \pm 18.1$ & & \\
\hline & Beer & $73(20.9)$ & $41.0 \pm 19.1$ & & & $63.3 \pm 20.6$ & & \\
\hline \multirow{2}{*}{$\begin{array}{l}\text { Tea consumption } \\
\quad(\mathrm{g} / \text { week })^{\mathrm{b}}\end{array}$} & $<50$ & $269(77.1)$ & $42.1 \pm 20.4$ & \multirow{2}{*}{0.755} & \multirow{2}{*}{0.451} & $63.5 \pm 21.8$ & \multirow{2}{*}{0.184} & \multirow{2}{*}{0.854} \\
\hline & $\geq 50$ & $80(22.9)$ & $40.2 \pm 19.2$ & & & $63.0 \pm 20.1$ & & \\
\hline \multirow{2}{*}{ Coffee drinking ${ }^{\mathrm{b}}$} & No & $345(98.9)$ & $41.8 \pm 20.0$ & \multirow{2}{*}{1.173} & \multirow{2}{*}{0.241} & $63.4 \pm 21.4$ & \multirow{2}{*}{0.282} & \multirow{2}{*}{0.778} \\
\hline & Yes & $4(1.1)$ & $29.9 \pm 26.0$ & & & $60.4 \pm 26.7$ & & \\
\hline \multirow{2}{*}{ Cola drinking ${ }^{\mathrm{b}}$} & No & $325(93.1)$ & $40.9 \pm 19.9$ & \multirow{2}{*}{-2.463} & \multirow{2}{*}{$0.014^{*}$} & $62.7 \pm 21.3$ & \multirow{2}{*}{-2.160} & \\
\hline & Yes & $24(6.9)$ & $51.3 \pm 20.1$ & & & $72.5 \pm 21.2$ & & 0.001 \\
\hline 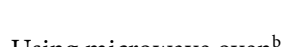 & No & $223(63.9)$ & $39.7 \pm 20.3$ & & & $61.4 \pm 21.8$ & & \\
\hline 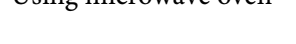 & Yes & $126(36.1)$ & $45.0 \pm 19.3$ & -2.500 & 0.018 & $66.8 \pm 20.4$ & -2.200 & 0.024 \\
\hline Using plastic bags for & No & $272(77.9)$ & $42.9 \pm 20.3$ & 202 & $0020^{*}$ & $64.9 \pm 21.3$ & 170 & $0011^{*}$ \\
\hline meat food storage $\mathrm{e}^{\mathrm{b}}$ & Yes & $77(22.1)$ & $37.1 \pm 18.8$ & 2.202 & 0.027 & $58.1 \pm 21.1$ & 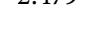 & 0.014 \\
\hline & $0-2$ & $123(35.2)$ & $43.5 \pm 20.1$ & & & $64.4 \pm 20.5$ & & \\
\hline $\begin{array}{c}\text { Fruit intake } \\
\text { (times/week) }\end{array}$ & $3-5$ & $73(20.9)$ & $39.8 \pm 17.9$ & 0.928 & 0.396 & $61.4 \pm 19.1$ & 0.544 & 0.581 \\
\hline & $\geq 6$ & $153(43.8)$ & $41.0 \pm 21.1$ & & & $63.5 \pm 23.2$ & & \\
\hline Celerv intakeb & No & $278(79.7)$ & $40.5 \pm 20.3$ & 17 & $00020 *$ & $62.2 \pm 21.7$ & & \\
\hline 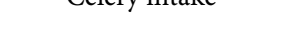 & Yes & $71(20.3)$ & $46.2 \pm 18.6$ & 2.147 & 0.002 & $67.9 \pm 19.8$ & 1.J & 0.047 \\
\hline & Never & $54(15.5)$ & $46.3 \pm 20.6$ & & & $67.4 \pm 21.4$ & & \\
\hline & 1 - 2 times/month & $86(24.6)$ & $43.9 \pm 19.1$ & & & $65.3 \pm 20.1$ & & \\
\hline & 3 - 4 times/month & $30(8.6)$ & $41.2 \pm 17.8$ & & & $63.8 \pm 17.4$ & & \\
\hline Exercise or $20 \mathrm{~min}$ & 1 - 2 times/week & $53(15.2)$ & $38.8 \pm 21.1$ & 1.330 & 0.248 & $59.8 \pm 23.2$ & 0.944 & 0.430 \\
\hline & 3 - 5 times/week & $33(9.5)$ & $39.1 \pm 19.2$ & & & $61.8 \pm 21.8$ & & \\
\hline & Everyday & $93(26.6)$ & $39.5 \pm 21.0$ & & & $61.8 \pm 22.6$ & & \\
\hline Bicucling of $20 \mathrm{~min}^{\mathrm{b}}$ & No & $259(74.2)$ & $41.3 \pm 19.9$ & 0 & $0-507$ & $63.2 \pm 21.3$ & 10 & 0757 \\
\hline & Yes & $90(25.8)$ & $42.6 \pm 20.8$ & 0.520 & - & $64.0 \pm 21.9$ & -0.310 & 0.737 \\
\hline & $<3$ & $118(33.8)$ & $45.5 \pm 19.5$ & & & $67.2 \pm 20.5$ & & \\
\hline Sedentary time $(\mathrm{h} / \text { day })^{\mathrm{a}}$ & $3-5$ & $148(42.4)$ & $39.2 \pm 19.4$ & 3.459 & $0.033^{*}$ & $61.0 \pm 21.0$ & 3.110 & $0.047^{*}$ \\
\hline & $\geq 5$ & $83(23.8)$ & $40.6 \pm 21.5$ & & & $62.1 \pm 23.1$ & & \\
\hline & $<6$ & $86(24.6)$ & $43.7 \pm 19.5$ & & & $65.8 \pm 20.2$ & & \\
\hline Sleeping time $(\mathrm{h} / \text { day })^{\mathrm{a}}$ & $6-8$ & $118(33.8)$ & $39.4 \pm 20.4$ & 1.252 & 0.287 & $61.1 \pm 22.3$ & 1.238 & 0.291 \\
\hline & $\geq 8$ & $145(41.5)$ & $42.3 \pm 20.2$ & & & $63.8 \pm 21.4$ & & \\
\hline
\end{tabular}

SD: Standard deviation; ${ }^{\mathrm{a} O n e-w a y ~ a n a l y s i s ~ o f ~ v a r i a n c e ~ w a s ~ u s e d ; ~}{ }^{\mathrm{b}}$ Independent-samples $\mathrm{t}$-test was used; ${ }^{*} \mathrm{P}<0.05$. 
Table 3. Multivariate analysis of sperm motility.

\begin{tabular}{|c|c|c|c|c|c|}
\hline \multirow{2}{*}{ Subject } & & \multicolumn{2}{|c|}{ Progressive motility (PR, \%) } & \multicolumn{2}{|c|}{ Total motility (PR+NP, \%) } \\
\hline & & $\beta(95 \% \mathrm{CI})$ & $\mathbf{P}$ & $\beta(95 \% \mathrm{CI})$ & $\mathbf{P}$ \\
\hline & Others & Ref & & Ref & \\
\hline \multirow[t]{2}{*}{ Job title } & Industry workers & $-5.64(-11.21,-0.07)$ & $0.047^{*}$ & $-7.96(-13.94,-1.98)$ & $0.009 *$ \\
\hline & Farmers & $-1.48(-6.33,3.37)$ & 0.550 & $-1.79(-7.00,3.41)$ & 0.499 \\
\hline \multirow{2}{*}{$\begin{array}{l}\text { With organic reproductive } \\
\text { diseases }\end{array}$} & No & Ref & & Ref & \\
\hline & Yes & $-6.14(-11.00,-1.28)$ & $0.013^{*}$ & $-4.62(-10.23,0.99)$ & 0.106 \\
\hline \multirow{2}{*}{ Cola drinking } & No & Ref & & Ref & \\
\hline & Yes & $9.71(1.46,17.96)$ & $0.021^{*}$ & $8.37(-0.48,17.23)$ & 0.064 \\
\hline \multirow{2}{*}{ Using microwave oven } & No & Ref & & Ref & \\
\hline & Yes & $4.12(-0.26,8.51)$ & 0.065 & $4.22(-0.49,8.93)$ & 0.079 \\
\hline \multirow{2}{*}{$\begin{array}{l}\text { Using plastic bags for meat food } \\
\text { storage }\end{array}$} & No & Ref & & Ref & \\
\hline & Yes & $-5.56(-10.61,-0.51)$ & $0.031^{*}$ & $-6.37(-11.79,-0.95)$ & $0.021^{*}$ \\
\hline \multirow{2}{*}{ Celery intake } & No & Ref & & Ref & \\
\hline & Yes & $7.00(1.59,12.42)$ & $0.011^{*}$ & $7.26(1.45,13.07)$ & $0.015^{*}$ \\
\hline \multirow{3}{*}{ Sedentary time (h/day) } & $<3$ & Ref & & Ref & \\
\hline & $3-5$ & $-5.92(-10.66,-1.17)$ & $0.015^{*}$ & $-5.51(-10.60,-0.42)$ & $0.034^{*}$ \\
\hline & $\geq 5$ & $-6.04(-11.60,-0.47)$ & $0.034^{*}$ & $-6.03(-12.01,-0.06)$ & $0.048^{*}$ \\
\hline
\end{tabular}

CI: Confidence interval; Ref: Reference; ${ }^{*} \mathrm{P}<0.05$.

\section{Discussion}

Our present study showed that dietary celery intake, cola consumption increased the PR and/or PR + NP of sperm, while using plastic bags for meat food storage, industry work, organic disease and sedentary lifestyle decreased the index.

Celery is a homely food material in China and was habitually used as condiment or spice in the local recipe. It is an important herb to the traditional Chinese medicine, and was recorded in the ancient Chinese medicine book "Newly Revised Materia Medica" (Xinxiu Bencao) on its medicinal value in 659 AD [12]. Modern medical studies have shown that aqueous extract of celery leaves promoted sperm production in rats [13] in a dose-dependent manner, and celery oil (A. graveolens) relieved testicular injury induced by diethyl phthalate [14]. Celery possibly improves human semen quality by its antioxidant effects [15] because of its abundance of apigenin, carotene and vitamins, etc. Anyway, it must be noted that celery (Apium graveolens L.) refers to Qin-Cai (A. graveolens var. secalinum) locally, a kind of vegetable between celery (A. graveolens var. dulce) and coriander, with strong fragrant smell, usually used as a condiment or spice in the local cuisines [16].

Cola consumption was found to be associated with higher PR in this study and is accordant to the study by Pokhrel et al. [17] on young Chinese men, and among them higher PR + NP was also found in that study, though not observed 
in our present study. A relevant research also reported that caffeinated beverage (e.g., coffee and cola) increased sperm motility [18], though opposite results existed [6] [19]. The discordant associations of cola or coffee consumption with PR may be explained by the fairly low consumption of coffee and cola by the population of our study, e.g., few (no more than $8.0 \%$ ) people consumed coffee or cola. Anyway, given the very little caffeine contained in cola $(70 \mathrm{mg}$ in $0.5 \mathrm{~L}$ ), the increase of sperm motility could be attributed to both caffeine and other ingredients such as sugar [20].

Our study showed that the use of plastic bags for meat food storage was associated with the decrease of PR and PR + NP. Many local people know little about the fact that polyvinyl chloride (PVC) film bags contain harmful chemicals such as bisphenol A (BPA), so they used PVC plastic bags to store food indiscriminately. The chemicals in plastic bags could leak out and contaminate food. The chemicals entered and accumulated in human body via food and drink, finally leading to adverse effects including reproductive toxicity which was manifested as reduced sperm motility [21].

Occupation category is found to be associated with sperm motility in the present study. Industry workers had lower PR and PR+NP than those with other job categories including business services, education, and freelancing. However, sperm motility was not significant different between workers and farmers. This may be related to workers and farmers shared some common exposures such as airborne PM2.5 [22], lead, cadmium, chromium, pesticides [23] [24].

Organic diseases of the reproductive system (e.g., varicocele, prostatitis, cryptorchidism) is observed as risk factors for poor semen quality such as decreased sperm concentration, motility in many studies [17] [25], which is in line with our research results.

The effects of physical activity and sedentary lifestyle on semen quality have received a lot of attention but shown contradictory results in recent year [17] [26], though inconsistent. Our present research indicated that sperm motility in the sedentary group (i.e., prolonged sitting $\geq 3 \mathrm{~h}$ /day) was lower than that of men who did not, but there was no significantly transformational trend with exercise levels.

Negative effects of age, smoking, drinking [3], and abnormal BMI [27] on semen quality have been reported, but not always consistent among studies [17]. Our investigation did not show the links. The reasons for this discrepancy may be: 1) ethnic minorities account for a relatively high proportion in this study (the proportions of Han ethnic vs Zhuang ethnic are $91.5 \%$ vs $1.28 \%$ nationally, but $44.2 \%$ vs $42.4 \%$ in the present study, similar to that of this region), possibly resulting in lessened comparability; 2) type and intensity of smoking and drinking in this population are a bit different from other studies, e.g., local people prefer locally produced rice wine to blend wine, locally handmade tobacco to cigarettes; 3) because of the limitation of the relatively small sample and the insufficient further detailed data, some links among variables were not discovered, e.g., 
physical work among the subjects was not quantitatively assessed, and coffee drinking was not a popular lifestyle.

Because of the cross-sectional design, small sample volume, ethnic composition of the study population, statistical efficiency of the study decreased to some extent. However, the project in the ethnic minority region extended some new findings, and our study expands the knowledge on male infertility and its associations with possible risk factors. Because the lifestyle of the local population is changing quickly, we would suggest that a multicenter prospective study should be conducted to further clarify the relationship between lifestyle and human sperm motility in this district, so that effective intervention could be provided to protect and improve the quality of human semen.

\section{Conclusion}

Modifiable lifestyle factors such as job title, cola consumption, dietary celery intake, plastic bags for meat food storage, and sedentary lifestyle were related to progressive motility or total motility. Further multicenter prospective studies on this issue are needed to develop effective interventions to improve the quality of human semen.

\section{Authors' Contributions}

Yonghua HE designed the study. Jia LIU, Liangzhao LIU and Jingyu LI collected data. Linfeng MO and Junyi TANG performed the statistical analyses. Linfeng MO wrote the paper. All authors were involved in paper revision and gave final approval.

\section{Acknowledgements}

We should give special thanks to Lin Wang for his great coordination so that the project could go on smoothly.

\section{Ethical Considerations \& Disclosure(s)}

All procedures conducted in this study were obtained the appropriate approval by the Ethics Committee of Guilin Medical University (NO. GLMC201603026) and that the subjects gave informed consent.

\section{Funding Sources}

This study was supported by the [National Natural Science Foundation of China]; under Grant [81660264] and the [Natural Science Foundation of Guangxi] under Grant [2020GXNSFDA297028].

\section{Conflicts of Interest}

The authors declare no conflicts of interest regarding the publication of this paper. 


\section{References}

[1] Smith, R.P., Coward, R.M. and Lipshultz, L.I. (2014) The Office Visit. Urologic Clinics of North America, 41, 19-37. https://doi.org/10.1016/j.ucl.2013.08.002

[2] Carlsen, E., Giwercman, A., Keiding, N. and Skakkebaek, N.E. (1992) Evidence for Decreasing Quality of Semen during Past 50 Years. British Medical Journal, 305, 609-613. https://doi.org/10.1136/bmj.305.6854.609

[3] Li, Y., Lin, H., Li, Y.F. and Cao, J. (2011) Association between Socio-PsychoBehavioral Factors and Male Semen Quality: Systematic Review and Meta-Analyses. Fertility and Sterility, 95, 116-123. https://doi.org/10.1016/j.fertnstert.2010.06.031

[4] Kaya, C., Aykac, A., Kaya, Y. and Tas, M. (2020) The Effect of Modifiable Lifestyle Factors on Semen Quality. Revista Internacional de Andrología, 18, 151-158. https://doi.org/10.1016/j.androl.2019.09.001

[5] Povey, A.C., Clyma, J.A., McNamee, R., Moore, H.D., Baillie, H., et al. (2012) Modifiable and Non-Modifiable Risk Factors for Poor Semen Quality: A Case-Referent Study. Human Reproduction, 27, 2799-2806.

https://doi.org/10.1093/humrep/des183

[6] Jensen, T.K., Swan, S.H., Skakkebaek, N.E., Rasmussen, S. and Jorgensen, N. (2010) Caffeine Intake and Semen Quality in a Population of 2,554 Young Danish Men. American Journal of Epidemiology, 171, 883-891. https://doi.org/10.1093/aje/kwq007

[7] Zhong, Y.X., Liu, Z.H., Cheng, H.Y., Liao, Y.H., Chen, K., et al. (2015) Analysis on Illicium verum Intake of Different Regions in Guangxi. Chinese Journal of Public Health Engineering, 14, 33-35. (In Chinese)

[8] Xie, W., Qin, W., Mo, Y., Liao, X., Wang, T., et al. (2015) Evaluation of semen quality in normal fertility men from Guangxi Zhuang Autonomous Region. Journal of Modern Medical Health, 31, 1466-1469. (In Chinese)

[9] Tan, D.X., Mo, Y., Xie, D.N., Zhang, S.C., Lv, F.T., et al. (2012) The Research on Semen Quality from Males with Normal Fertility in Guangxi Region. Chinese Journal of Family Planning \& Gynecotokology, 4, 9-12. (In Chinese)

[10] World Health Organization (2010) WHO Laboratory Manual for the Examination and Processing of Human Semen. 5th Edition, WHO, Geneva.

[11] De-Jonge, C., LaFromboise, M., Bosmans, E., Ombelet, W., Cox, A., et al. (2004) Influence of the Abstinence Period on Human Sperm Quality. Fertility and Sterility, 82, 57-65. https://doi.org/10.1016/j.fertnstert.2004.03.014

[12] Sun, X.S. (2011) Academic Contribution of "Xinxiu Bencao" and Its HealthPreserving Fruits and Vegetables. Journal of New Chinese Medicine, 43, 145-147. (In Chinese)

[13] Hardani, A., Afzalzadeh, M.R., Amirzargar, A., Mansouri, E. and Meamar, Z. (2015) Effects of Aqueous Extract of Celery (Apium graveolens L.) Leaves on Spermatogenesis in Healthy Male Rats. Avicenna Journal of Phytomedicine, 5, 113-119.

[14] Helal, M.A. (2014) Celery Oil Modulates DEHP-Induced Reproductive Toxicity in Male Rats. Reproductive Biology, 14, 182-189. https://doi.org/10.1016/j.repbio.2014.04.002

[15] Salas-Huetos, A., Bullo, M. and Salas-Salvado, J. (2017) Dietary Patterns, Foods and Nutrients in Male Fertility Parameters and Fecundability: A Systematic Review of Observational Studies. Human Reproduction Update, 23, 371-389. https://doi.org/10.1093/humupd/dmx006 
[16] Malhotra, S.K. (2012) Celery. In: Peter, K.V., Ed., Handbook of Herbs and Spices, 2th Edition, Woodhead Publishing Ltd., Cambridge, UK, 249-267. https://doi.org/10.1533/9780857095688.249

[17] Pokhrel, G., Yihao, S., Wangcheng, W., Khatiwada, S.U., Zhongyang, S., et al. (2019) The Impact of Sociodemographic Characteristics, Lifestyle, Work Exposure and Medical History on Semen Parameters in Young Chinese Men: A Cross-Sectional Study. Andrologia, 51, e13324. https://doi.org/10.1111/and.13324

[18] Yang, H., Chen, Q., Zhou, N., Sun, L., Bao, H., et al. (2015) Lifestyles Associated With Human Semen Quality: Results from MARHCS Cohort Study in Chongqing, China. Medicine (Baltimore), 94, e1166. https://doi.org/10.1097/MD.0000000000001166

[19] Ricci, E., Vigano, P., Cipriani, S., Somigliana, E., Chiaffarino, F., et al. (2017) Coffee and Caffeine Intake and Male Infertility: A Systematic Review. Nutrition Journal, 16, Article No. 37. https://doi.org/10.1186/s12937-017-0257-2

[20] Chiu, Y.H., Afeiche, M.C., Gaskins, A.J., Williams, P.L., Mendiola, J., et al. (2014) Sugar-Sweetened Beverage Intake in Relation to Semen Quality and Reproductive Hormone Levels in Young Men. Human Reproduction, 29, 1575-1584. https://doi.org/10.1093/humrep/deu102

[21] Li, D.K., Zhou, Z., Miao, M., He, Y., Wang, J., et al. (2011) Urine Bisphenol-A (BPA) Level in Relation to Semen Quality. Fertility and Sterility, 95, 625-630.E4. https://doi.org/10.1016/j.fertnstert.2010.09.026

[22] Lao, X.Q., Zhang, Z., Lau, A.K.H., Chan, T.C., Chuang, Y.C., et al. (2018) Exposure to Ambient Fine Particulate Matter and Semen Quality in Taiwan. Occupational \& Environmental Medicine, 75, 148-154. https://doi.org/10.1136/oemed-2017-104529

[23] Hauser, R. and Sokol, R. (2008) Science Linking Environmental Contaminant Exposures with Fertility and Reproductive Health Impacts in the Adult Male. Fertility and Sterility, 89, e59-e65. https://doi.org/10.1016/j.fertnstert.2007.12.033

[24] Sheiner, E.K., Sheiner, E., Hammel, R.D., Potashnik, G. and Carel, R. (2003) Effect of Occupational Exposures on Male Fertility: Literature Review. Industrial Health, 41, 55-62. https://doi.org/10.2486/indhealth.41.55

[25] Damsgaard, J., Joensen, U.N., Carlsen, E., Erenpreiss, J., Jensen, M.B., et al. (2016) Varicocele Is Associated with Impaired Semen Quality and Reproductive Hormone Levels: A Study of 7035 Healthy Young Men from Six European Countries. European Urology, 70, 1019-1029. https://doi.org/10.1016/j.eururo.2016.06.044

[26] Sun, B., Messerlian, C., Sun, Z.H., Duan, P., Chen, H.G., et al. (2019) Physical Activity and Sedentary Time in Relation to Semen Quality in Healthy Men Screened as Potential Sperm Donors. Human Reproduction, 34, 2330-2339.

https://doi.org/10.1093/humrep/dez226

[27] Sermondade, N., Faure, C., Fezeu, L., Shayeb, A.G., Bonde, J.P., et al. (2013) BMI in Relation to Sperm Count: An Updated Systematic Review and Collaborative MetaAnalysis. Human Reproduction Update, 19, 221-231.

https://doi.org/10.1093/humupd/dms050 